\title{
Methane distribution at high spatial resolution in North Sea estuaries
}

Ingeborg Bussmann, Holger Brix, Philipp Fischer, Götz Flöser 


\section{MOSES}

Modular Observation Solutions for Earth Systems

\section{Two Research vessels} Ludwig Prandtl Uthörn
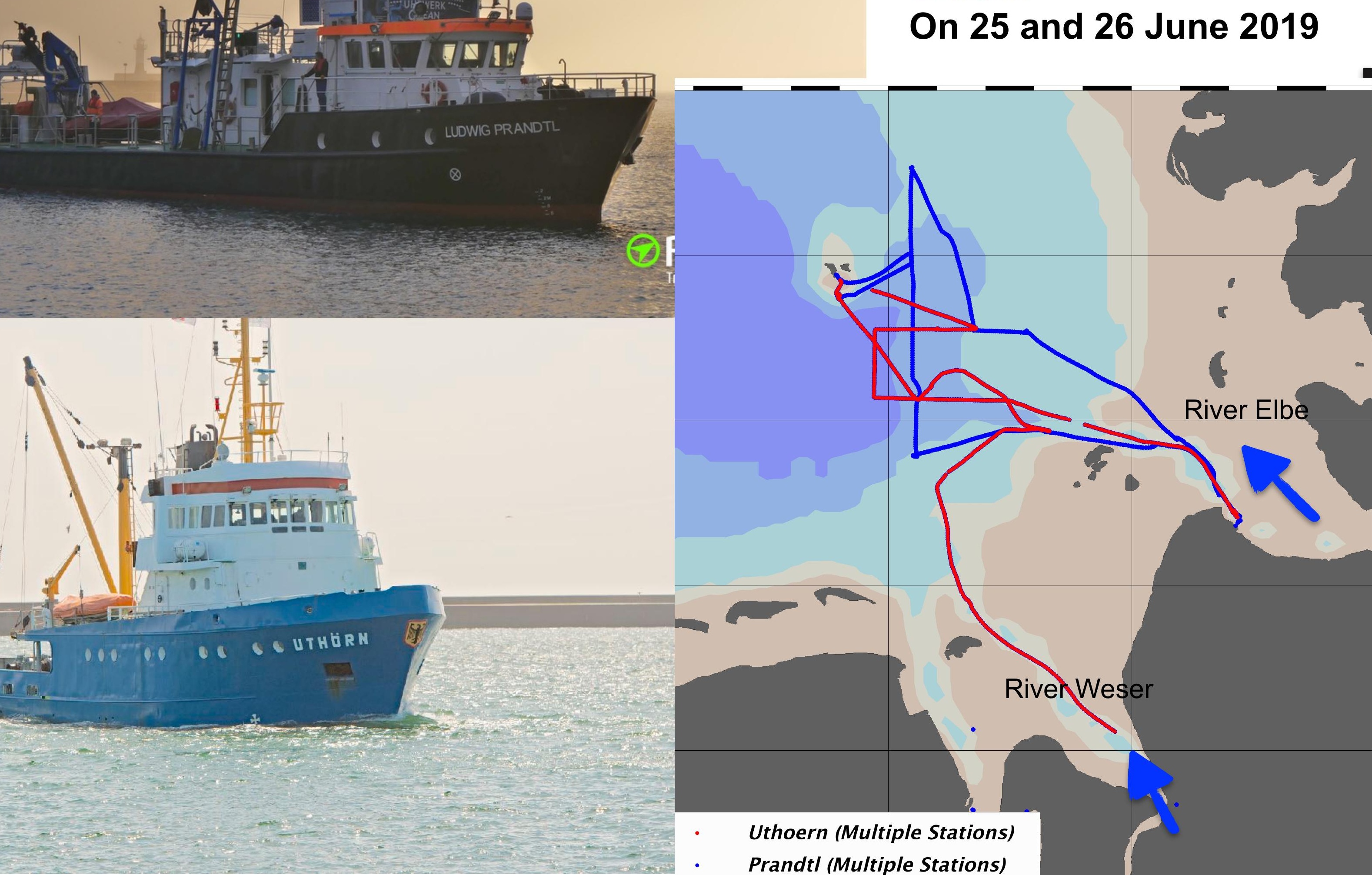


\section{Material \& Methods}

- Continuous, underway measurements

- Running water from board water pump

- Hydrographic parameters with FerryBox

- Methane:

- Gas extraction from water with a degassing unit

- Gas analysis with cavity ring down spectroscopy

- Determination of delay time(s)

- Calibration with water samples analyzed with head space and GC

- Intercalibration between ships !! 


\section{Overall Methane distribution in surface waters}

diss. methane [nmol / L] @ water depth [m]=first
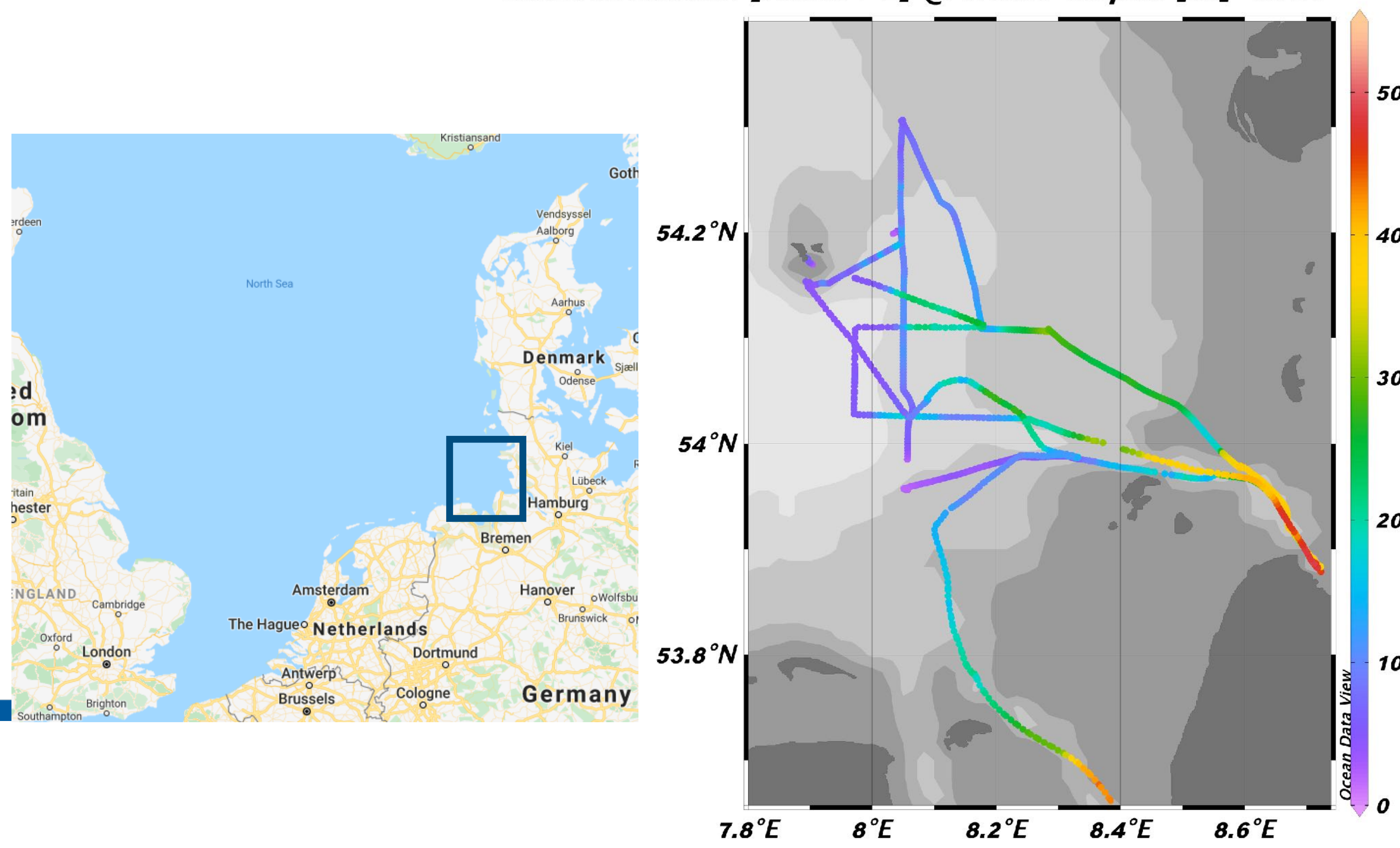


\section{Dilution of river water with marine end member}

Marine end member at $\mathrm{S}>32$ with $6.5 \mathrm{nM}$

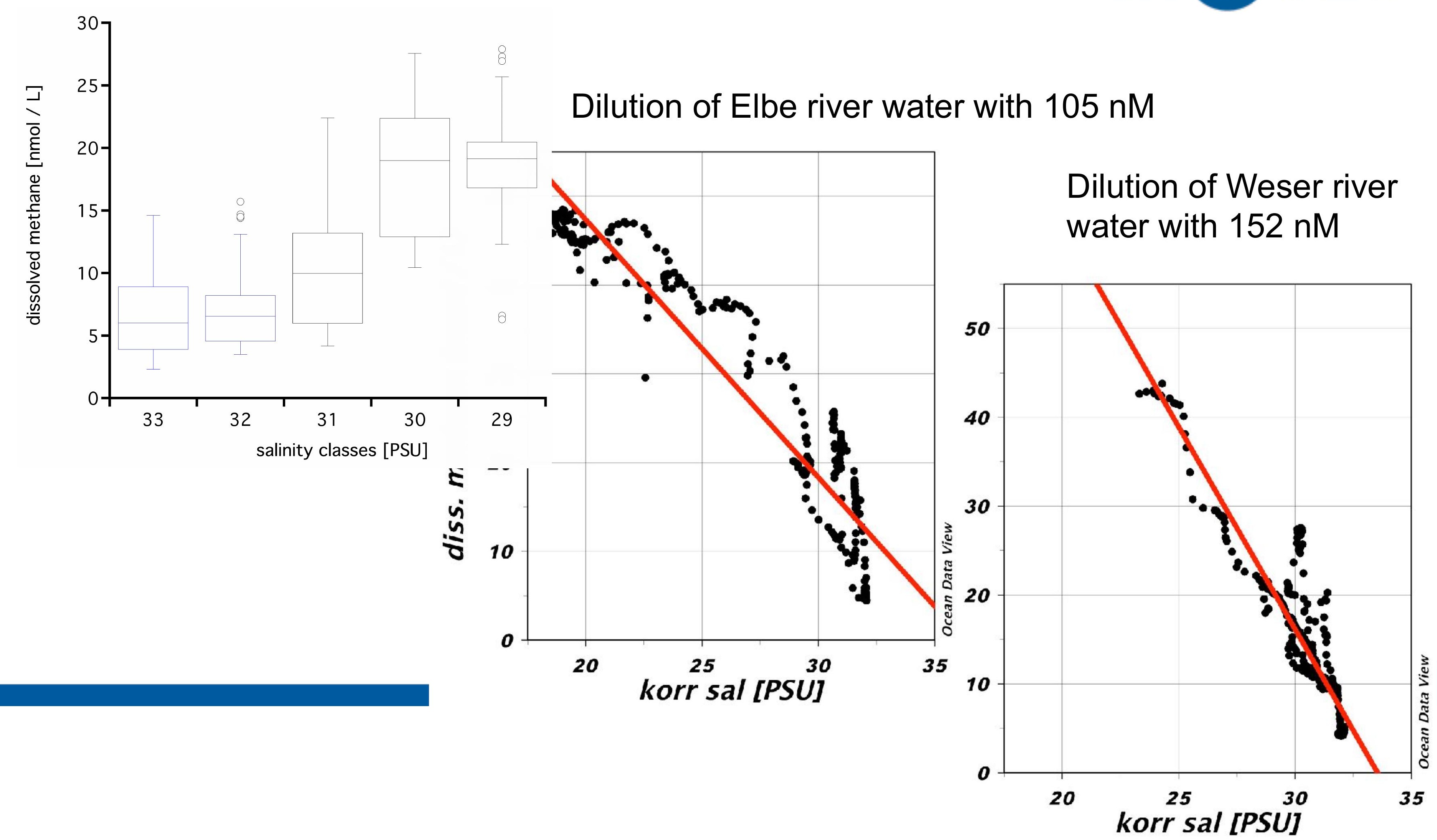




\section{Back-tracking of water masses}

- https://www.hzg.de/ drift-now

- Part of the water off Helgoland originated from the river "Weser" not only from the river „Elbe“

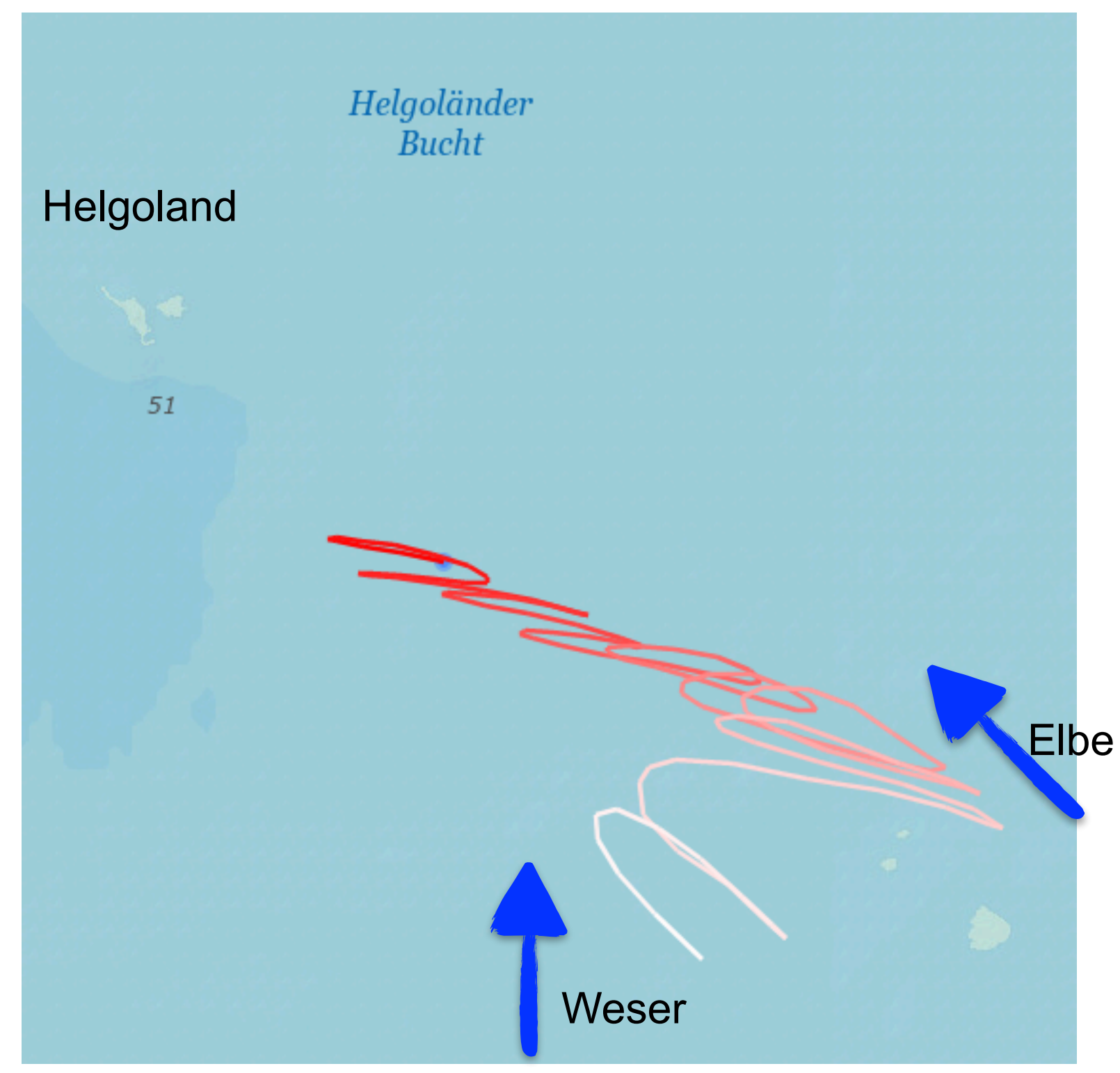




\section{Conclusions}

- New techniques to measure $\mathrm{CH}_{4}$ continuously and at longer time scales $=>$ new patterns

- Combination of data matrixes allows to model and explain the observed patters

- Challenges: data management and comparability between sensors

Thank you for your attention! 